\title{
Antibacterial and antioxidant activity of different types of honey derived from Mount Olympus in Greece
}

\author{
DIMITRIOS STAGOS $^{1}$, NIKOLAOS SOULITSIOTIS ${ }^{1}$, CHRISTINA TSADILA $^{1}$, \\ STAMATINA PAPAECONOMOU ${ }^{1}$, CHARALAMPOS ARVANITIS ${ }^{1}$, ALEXANDROS NTONTOS ${ }^{2}$, \\ FANI KARKANTA ${ }^{2}$, SOULTANA ADAMOU-ANDROULAKI ${ }^{2}$, KONSTANTINOS PETROTOS ${ }^{2}$, \\ DEMETRIOS A. SPANDIDOS ${ }^{3}$, DEMETRIOS KOURETAS ${ }^{1}$ and DIMITRIS MOSSIALOS ${ }^{1}$ \\ ${ }^{1}$ Department of Biochemistry and Biotechnology, University of Thessaly, Biopolis, 41500 Larissa; \\ ${ }^{2}$ Department of Biosystems Engineering, Technical Education Institute of Thessaly, 41110 Larissa; \\ ${ }^{3}$ Laboratory of Clinical Virology, Medical School, University of Crete, 71003 Heraklion, Crete, Greece
}

Received February 15, 2018; Accepted April 27, 2018

DOI: $10.3892 / \mathrm{ijmm} .2018 .3656$

\begin{abstract}
The aim of the present study was to examine the antioxidant and antibacterial activity of 21 types of honey derived from Mount Olympus (Mt. Olympus), a region with great plant biodiversity. The antibacterial activity was examined against the growth of Staphylococcus aureus (S. aureus) and Pseudomonas aeruginosa (P. aeruginosa) by the agar well diffusion assay and the determination of the minimum inhibitory concentration (MIC). The antioxidant activity was assessed by using the 2,2-diphenyl-1-picrylhydrazyl (DPPH) and 2,2'-azino-bis(3-ethylbenzothiazoline-6-sulphonic acid $\left(\mathrm{ABTS}^{\cdot+}\right)$ free radical scavenging assays. These activities were compared to Manuka honey which is used as an alternative medicine. The results revealed that all tested honey types exhibited antibacterial activity against $S$. aureus and P. aeruginosa. The MIC of the tested honey types against $S$. aureus ranged from 3.125 to $12.5 \%(\mathrm{v} / \mathrm{v})$, while MIC of Manuka honey was determined to be $6.25 \%(\mathrm{v} / \mathrm{v})$. The MIC values of the tested honey types against $P$. aeruginosa ranged from 6.25 to $12.5 \%(\mathrm{v} / \mathrm{v})$ and the MIC of Manuka honey was determined at $12.5 \%(\mathrm{v} / \mathrm{v})$. Moreover, the results suggested that the presence of hydrogen peroxide and proteinaceous compounds in the honey types accounted, at least in part, for the antibacterial
\end{abstract}

Correspondence to: Dr Dimitris Mossialos or Dr Dimitrios Stagos, Department of Biochemistry and Biotechnology, University of Thessaly, Biopolis, 41500 Larissa, Greece

E-mail: mosial@bio.uth.gr

E-mail: stagkos@med.uth.gr

Abbreviations: ABTS $^{\cdot+}, 2,2^{\prime}$-azino-bis(3-ethylbenzothiazoline-6sulphonic acid; ANOVA, analysis of variance; DPPH, 2,2-diphenyl1-picrylhydrazyl; GAE, gallic acid equivalent; HRP, horseradish peroxidase; MGO, methylglyoxal; MIC, minimum inhibitory concentration; RSC, radical scavenging capacity; TPC, total polyphenolic content

Key words: honey, antioxidant, antibacterial, Mount Olympus, Pseudomonas aeruginosa, Staphylococcus aureus, plant polyphenols activity. In addition, the total polyphenolic content (TPC) of the honey types seemed to contribute to the antibacterial activity against $P$. aeruginosa. Furthermore, some of the tested honey types exhibited potent free radical scavenging activity against DPPH and $\mathrm{ABTS}^{\circ+}$ radicals, which was greater than that of Manuka honey. The results indicated that not only the quantity, but also the quality of the polyphenols were responsible for the antioxidant activity. Moreover, four honey types exhibiting great antioxidant activity were converted to powder using a freeze drying method. The results indicated that following conversion to powder all honey types, apart from one, retained their antioxidant activity, although their TPC was reduced. On the whole, and at least to the best of our knowledge, the present study is the first that extensively examined the bioactivities of different types of honey derived from Mt. Olympus.

\section{Introduction}

Honey, a sweet natural product known for its nutritive value and beneficial health effects, is produced by honeybees (Apis mellifera L.) which directly select nectar from plants or from excretions of plant sucking insects (i.e., honeydew) (1). Honey is essentially a concentrated aqueous solution of carbohydrates, mainly fructose $(\sim 38 \%)$ and glucose $(\sim 31 \%)$ and other oligo- and polysaccharides, consisting $\sim 95 \%$ of the dry weight of honey (2). Apart from carbohydrates, honey contains $>200$ different compounds, such as enzymes (e.g., glucose oxidase and catalase), proteins, vitamins (e.g., vitamins $\mathrm{C}$ and E), amino and organic acids, lipids, minerals and phytochemicals (e.g., polyphenols) (2). Although these components constitute a minor part of honey, they significantly contribute to its beneficial effects on health (3). However, the chemical composition among different types of honey varies greatly due to the botanical and entomological source, as well as the climate and environmental conditions $(4,5)$.

Honey exhibits potent antibacterial activity; thus, its use in modern medicine represents an attractive alternative treatment to combat multidrug resistant pathogens $(6,7)$. The antibacterial activity of honey is attributable to different factors, including hydrogen peroxide, a low $\mathrm{pH}$ and high osmolarity $(7,8)$. 
Methylglyoxal (MGO) and the antibacterial peptide, bee defensin-1, have been identified as important factors of the antibacterial activity exerted by certain types of honey. Furthermore, it has been shown that the antibacterial factors of honey may exhibit overlapping activity (9-11). The antibacterial potency among different honey types is variable, primarily depending on its botanical, seasonal and geographical source, although harvesting, processing and storage conditions may affect the antibacterial properties of honey $(7,12)$.

Manuka honey originates from the Manuka bush (Leptospermum scoparium), an endemic plant grown in New Zealand. There are a number of studies documenting the antibacterial activity of Manuka honey against various bacterial pathogens $(7,13,14)$. However, recent studies on the antibacterial properties of diverse honey types produced worldwide have reported similar or superior antibacterial efficacy compared to Manuka honey. These findings have suggested that further research could identify medically useful honey types which may have distinct advantages over Manuka honey $(6,7,15,16)$.

Apart from the antibacterial effects of honey, its antioxidant properties are also considered important (17). The antioxidant activity of honey is attributed mainly to its polyphenols (e.g., flavonoids and phenolic acids), antioxidant enzymes (e.g., catalase and peroxidase), vitamins (e.g., vitamin C), Maillard reaction products (e.g., melanoidins), and carotenoids and amino acids (e.g., proline). Several studies have reported that the antioxidant compounds of honey may prevent oxidative stress-induced pathological conditions $(18,19)$.

It is known that the chemical composition of honey and consequently its bioactivity depends on the botanical source $(4,5)$. Therefore, investigating the bioactivity of different types of honey harvested in regions of high plant biodiversity is of great interest. The famous Mount Olympus (Mt. Olympus) in Greece, apart from its mythological interest, contains a very rich plant biodiversity due to special climatic conditions, where a high mountain $(2,918 \mathrm{~m})$ spreads next to the Aegean Sea $(20,21)$. Furthermore, Mt. Olympus is the meeting point of Mediterranean and Central European floras and it is a major refuge of ancient European species (20,21). In the Mt. Olympus area, $>1,500$ plant species have been recorded (i.e., $25 \%$ of Greek flora) of which 26 are endemic (20). Thus, the aim of this study was to examine the antibacterial and antioxidant activity of 21 different types of honey that were derived from the Mt. Olympus area, in comparison to Manuka honey.

\section{Materials and methods}

Honey samples. A total of 21 different types of honey, which were derived from the Olympus mountain area were provided by individual beekeepers and beekeeper associations. Each sample was assigned a unique reference number and details regarding the botanical source (if available), the geographical location and date of harvest were also recorded (Table I). Honey samples were stored in glass containers at room temperature in the dark. The identification of the botanical source of each honey type was performed by the providers based on the flora availability during the harvest season, the location of the apiary and, in some cases, pollen analysis. Manuka honey MGO 550+ (Manuka Health, Auckland, New Zealand) was used as a positive control throughout this study, while laboratory-synthesized honey was used as a negative control. Laboratory-synthesized honey was prepared by dissolving $3 \mathrm{~g}$ sucrose, $15 \mathrm{~g}$ maltose, $80.1 \mathrm{~g}$ fructose and $67 \mathrm{~g}$ glucose (all supplied by Sigma-Aldrich, Athens, Greece) in $34 \mathrm{ml}$ sterile deionised water. This solution was heated to $56^{\circ} \mathrm{C}$ in a water bath to aid dissolving, as previously described (7).

Bacterial strains and growth conditions. The antibacterial activity of the different types of honey was tested against methicillin-resistant Staphylococcus aureus (S. aureus) strain 1552 and carbapenem-resistant Pseudomonas aeruginosa (P. aeruginosa) strain 1773. Both clinical strains were identified and characterized by standard laboratory methods (kindly provided by Professor Spyros Pournaras, School of Medicine, University of Athens, Athens, Greece). The bacteria were routinely grown in Mueller-Hinton Broth (Lab M, Bury, $\mathrm{UK})$ or Mueller-Hinton agar (Lab M) at $37^{\circ} \mathrm{C}$.

Agar well diffusion assay. The assay was performed on the basis of the the Clinical and Laboratory Standards Institute (CLSI, former NCCLS) guidelines as previously described (7). Briefly, overnight bacterial cultures grown in Mueller-Hinton broth were adjusted to $0.5 \mathrm{McFarland}$ turbidity standard $\left(\sim 1.5 \times 10^{8} \mathrm{CFU} / \mathrm{ml}\right)$. Mueller-Hinton agar plates were inoculated with roughly $10^{6} \mathrm{CFUs}$ over the entire surface of the plate. Three wells of $6 \mathrm{~mm}$ in diameter were cut into the surface of the agar using a sterile cork borer. Subsequently, $100 \mu 1[50 \% \mathrm{v} / \mathrm{v}$ in phosphate-buffered saline (PBS)] of the tested honey types, Manuka honey and laboratory-synthesized honey were added separately to each well. The plates were incubated at $37^{\circ} \mathrm{C}$ for $16-18 \mathrm{~h}$. The diameter of the inhibition zones, including the diameter of the well, was recorded. The diameter of the inhibition zone, if present, in the negative control was recorded and subtracted from the inhibition zones of the tested, as well as of Manuka honey. Each assay was carried out in triplicate.

Determination of minimum inhibitory concentration (MIC). The minimum inhibitory concentration (MIC) of the honey types was determined in sterile 96 -well polystyrene microtiter plates (Kisker Biotech GmbH \& Co. KG, Steinfurt, Germany) using a spectrophotometric bioassay, as previously described (22). Briefly, overnight bacterial cultures grown in Mueller-Hinton broth were adjusted to a $0.5 \mathrm{McF}$ arland turbidity standard $\left(\sim 1.5 \times 10^{8} \mathrm{CFU} / \mathrm{ml}\right)$. Approximately $5 \times 10^{4}$ CFUs in $10 \mu 1$ Mueller-Hinton broth were added to $190 \mu \mathrm{l}$ of 2-fold diluted test honey (honey concentration ranged from 50 to $0.78 \% \mathrm{v} / \mathrm{v}$ ) in Mueller-Hinton broth. Two-fold serial dilutions of the same range of Manuka honey were included for comparison. The control wells contained only Mueller-Hinton broth-inoculated with bacteria. The optical density (OD) was determined at $630 \mathrm{~nm}$ using an ELx808 Absorbance microplate reader (BioTek Instruments, Inc., Winooski, VT, USA) just prior to incubation $(\mathrm{t}=0)$ and after $24 \mathrm{~h}$ of incubation $(\mathrm{t}=24)$ at $37^{\circ} \mathrm{C}$. The $\mathrm{OD}$ for each replicate well at $\mathrm{t}=0$ was subtracted from the OD of the same replicate well at $t=24$. The growth inhibition at each honey dilution was determined using the formula: $\%$ inhibition $=1-(\mathrm{OD}$ test well/OD of corresponding control well) $\mathrm{x} 100$. MIC was determined as the lowest honey concentration which results in $100 \%$ growth inhibition. 
Table I. Botanical source, geographical location, harvest date and TPC of the honey types.

\begin{tabular}{|c|c|c|c|c|}
\hline Honey number & Botanical source & Geographical location & Harvest date & $\mathrm{TPC}^{\mathrm{a}}$ \\
\hline 1 & Polyfloral & Karia & July, 2013 & 0.66 \\
\hline 2 & Alfalfa and herbs & Elassona & July, 2013 & 0.72 \\
\hline 3 & Polyfloral & Sikea & July, 2013 & 0.72 \\
\hline 4 & Oregano and herbs & Paliampela & July, 2013 & 0.92 \\
\hline 5 & Polyfloral & Domeniko & July, 2013 & 0.64 \\
\hline 6 & Polyfloral & Skamnia & July, 2013 & 0.78 \\
\hline 7 & Polyfloral & Sarantaporo & July, 2013 & 0.59 \\
\hline 8 & Mint, herbs and acacia & Krania & June, 2013 & 0.92 \\
\hline 9 & Polyfloral & Azoro & July, 2013 & 0.71 \\
\hline 10 & Polyfloral & Verdikoussia & July, 2013 & 0.67 \\
\hline 11 & Polyfloral & Kalithea & July, 2013 & 0.55 \\
\hline 12 & Polyfloral & Karia & June, 2012 & 0.67 \\
\hline 13 & Polyfloral and chestnut & Lechonia & 2013 & 0.61 \\
\hline 14 & Polyfloral and conifers & Domeniko & 2012 & 0.71 \\
\hline 15 & Polyfloral & Karia & July, 2014 & $\mathrm{ND}^{\mathrm{b}}$ \\
\hline 16 & Polyfloral & Elassona & 2012 & ND \\
\hline 17 & Herbs & Drimos & 2014 & ND \\
\hline 18 & Acacia, Abies and Sideritis & Karia & August, 2014 & ND \\
\hline 19 & Polyfloral and conifers & Azoros & August, 2014 & ND \\
\hline 20 & Polyfloral and conifers & Galanovrissi & 2014 & ND \\
\hline 21 & Polyfloral and conifers & Karia & July, 2014 & ND \\
\hline Manuka & - & - & - & 0.71 \\
\hline
\end{tabular}

${ }^{\mathrm{a}} \mathrm{TPC}$ was expressed as mg of gallic acid/g sample. ${ }^{\mathrm{b}} \mathrm{ND}$, not determined. TPC, total polyphenolic content.

Determination of whether the antibacterial activity is attributed to hydrogen peroxide and proteinaceous compounds. The MIC values of the honey types treated with bovine catalase or proteinase $\mathrm{K}$ was determined and compared to those of untreated honey, as previously described (10). Briefly, $50 \% \mathrm{v} / \mathrm{v}$ honey in Muller-Hinton broth containing $100 \mu \mathrm{g} / \mathrm{ml}$ proteinase $\mathrm{K}$ (HT Biotechnology, Cambridge, UK) or $600 \mathrm{U} / \mathrm{ml}$ bovine catalase (Serva, Heidelberg, Germany) was incubated for $16 \mathrm{~h}$ at $37^{\circ} \mathrm{C}$, and then it was 2 -fold diluted and tested as described above. The elevated MIC values of the treated honey compared to the untreated honey revealed the presence of hydrogen peroxide and /or proteinaceous compounds which contributed to the antibacterial activity of the tested honey types.

Determination of free radical-scavenging ability by the use of the 2,2-diphenyl-1-picrylhydrazyl (DPPH) radical assay. The DPPH radical scavenging activity of the honey samples was evaluated as previously described (23). Briefly, a $1 \mathrm{ml}$ freshly prepared methanolic solution of DPPH radical $(100 \mu \mathrm{M})$ was mixed with tested honey types at different concentrations following dilution in distilled water. The contents were vigorously mixed, incubated at room temperature in the dark for $20 \mathrm{~min}$ and the absorbance was read at $517 \mathrm{~nm}$. In each experiment, the tested sample alone in methanol was used as blank and DPPH radical alone in methanol was used as control. The percentage of radical scavenging capacity (RSC) of the tested samples was calculated according to the following equation: $\operatorname{RSC}(\%)=\left[\left(\mathrm{A}_{\text {control }}-\mathrm{A}_{\text {sample }}\right) / \mathrm{A}_{\text {control }}\right] \times 100$, where $\mathrm{A}_{\text {control }}$ and
$\mathrm{A}_{\text {sample }}$ are the absorbance values of the control and the tested samples, respectively. Moreover, in order to compare the radical scavenging efficiency of the samples, the $\mathrm{IC}_{50}$ value showing the concentration that caused 50\% scavenging of DPPH radical was calculated from the graph plotted RSC percentage against sample concentration. All experiments were carried out in triplicate and at least on 2 separate occasions.

Determination of free radical scavenging ability by the use of the 2,2'-azino-bis(3-ethylbenzothiazoline-6-sulphonic acid) $\left(\right.$ ABTS $\left.^{+}\right)$radical cation assay. The free radical-scavenging activity of the honey samples was also determined by ABTS radical cation $\left(\mathrm{ABTS}^{\circ+}\right.$ ) decolorization assay as previously described by Cano et al (24), with some modifications. In brief, $\mathrm{ABTS}^{*+}$ radical was produced by mixing $2 \mathrm{mM}$ ABTS with $30 \mu \mathrm{M} \mathrm{H}_{2} \mathrm{O}_{2}$ and $6 \mu \mathrm{M}$ horseradish peroxidase (HRP) enzyme in $50 \mathrm{mM}$ PBS (pH 7.5). Immediately, following the addition of the HRP enzyme, the contents were vigorously mixed, incubated at room temperature in the dark and the reaction was monitored at $730 \mathrm{~nm}$ until stable absorbance was obtained. Subsequently, $10 \mu 1$ of different sample concentrations diluted in distilled water were added in the reaction mixture and the decrease in absorbance at $730 \mathrm{~nm}$ was measured. In each experiment, the tested sample alone containing $1 \mathrm{mM}$ ABTS and $30 \mu \mathrm{M} \mathrm{H}_{2} \mathrm{O}_{2}$ in $50 \mathrm{mM}$ PBS ( $\mathrm{pH} 7.5$ ) was used as a blank, while the formed $\mathrm{ABTS}^{-+}$radical solution alone with $10 \mu 1 \mathrm{H}_{2} \mathrm{O}$ was used as a control. The RSC percentage and the $\mathrm{IC}_{50}$ values were determined as described above for the DPPH 


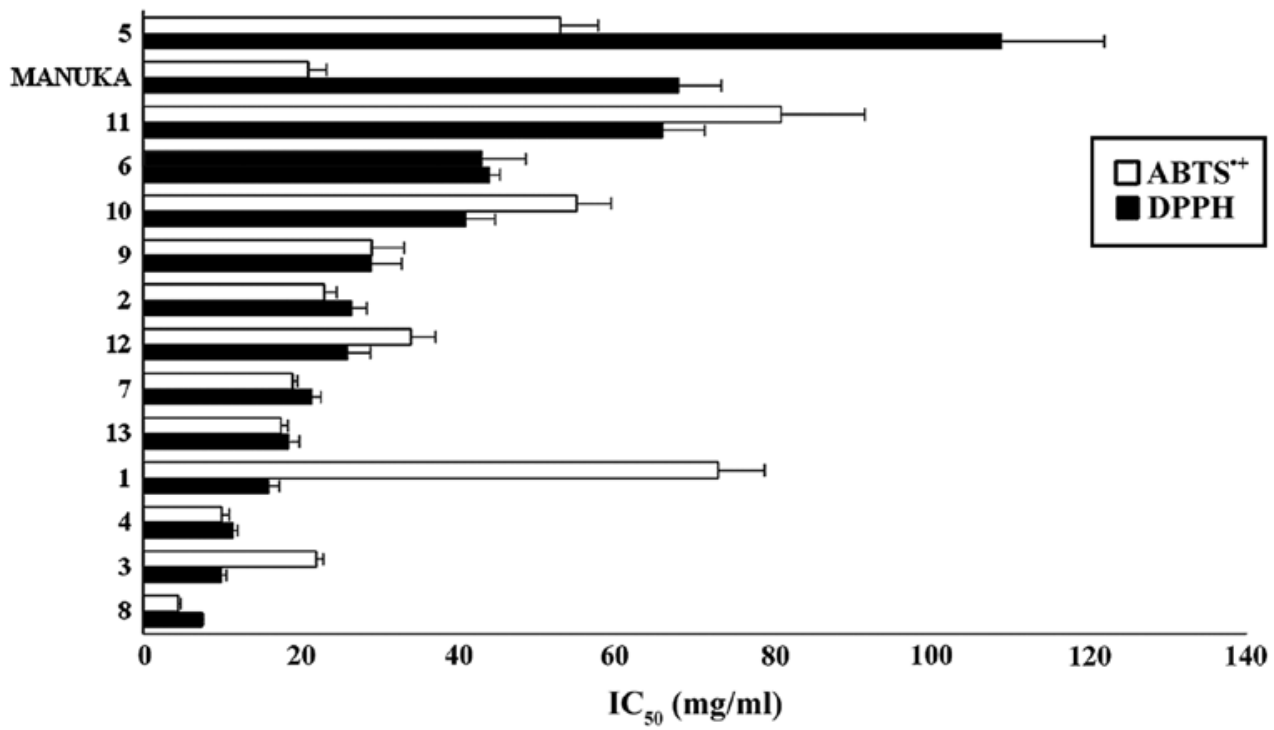

Figure 1. $\mathrm{IC}_{50}$ values of honey samples against DPPH and $\mathrm{ABTS}^{*+}$ radical scavenging. Values are presented as the means $\pm \mathrm{SD}$. ABTS ${ }^{\bullet+}, 2,2^{\prime}$-azino-bis(3-ethylbenzothiazoline-6-sulphonic acid; DPPH, 2,2-diphenyl-1-picrylhydrazyl.

method. All experiments were carried out in triplicate and at least on 2 separate occasions.

Assessment of the total phenolic content (TPC). The TPC of the honey samples was determined in accordance with a modified version of the Folin-Ciocalteu method (25). A $20 \mu \mathrm{l}$ of the sample was added to a tube containing $1 \mathrm{ml}$ of deionized water. Subsequently, $100 \mu \mathrm{l}$ of Folin-Ciocalteu reagent were added to the mixture, and the flask was stoppered and allowed to stand at room temperature for $3 \mathrm{~min}$. Thereafter, $280 \mu \mathrm{l}$ of $25 \% \mathrm{w} / \mathrm{v}$ sodium carbonate solution and $600 \mu \mathrm{l}$ of deionized water were added to the mixture. Following $1 \mathrm{~h}$ of incubation at room temperature in the dark, the absorbance was measured at $765 \mathrm{~nm}$ versus a blank containing Folin-Ciocalteu reagent and deionized water without the tested sample. The measurement of absorbance was conducted on a Hitachi U-1900 radio beam spectrophotometer (serial no. 2023-029; Anadrasi S.A., Thessaloniki, Greece). The optical density of the sample $(20 \mu \mathrm{l})$ in $25 \% \mathrm{w} / \mathrm{v}$ solution of sodium carbonate $(280 \mu \mathrm{l})$ and distilled water $(1.7 \mathrm{ml})$ at $765 \mathrm{~nm}$ was also measured. The TPC was determined using a standard curve of absorbance values correlated with standard concentrations $(50-1,500 \mu \mathrm{g} / \mathrm{ml})$ of gallic acid. The results are expressed as gallic acid equivalents (GAEs) using the standard curve (absorbance versus concentration) prepared from authentic gallic acid.

Preparation of honey powder using the freeze drying method. Four of the tested honey types (nos. 3, 4, 7 and 8), which were among the 6 and 5 most potent samples in DPPH and ABTS ${ }^{*+}$ assays, respectively (Fig. 1) were converted to powder using freeze drying. The freeze drying of honey was carried out by using a bench scale lyophilization unit type Scan Vac Labogene (4 1) at a very low temperature $\left(-110^{\circ} \mathrm{C}\right)$ and high vacuum $(\sim 0.5 \mathrm{mbar})$ for $48 \mathrm{~h}$. The material for freeze drying was prepared by mixing and homogenizing $180 \mathrm{~g}$ of water, $30 \mathrm{~g}$ of honey, $30 \mathrm{~g}$ of maltodextrin DE18 and $0.2 \mathrm{~g}$ of colloidal silicone dioxide. The homogenized material was filled in the glass jars, put in the freeze for $2 \mathrm{~h}$ and then was loaded in the freeze dryer to undergo the lyophilization cycle. The dry cake which was produced after completion of the drying cycle was grinded and converted to a fine powder which was used for the following experimentation.

Statistical analysis. All results are expressed as the means \pm SD $(n=3)$. For statistical analysis, one-way analysis of variance (ANOVA) was applied followed by Dunnett's test for post hoc analysis. All correlation analyses were made using Spearman's correlation analysis. Values of $\mathrm{P}<0.05$ were considered to indicate statistically significant differences. All statistical analyses were performed with the SPSS version 13.0 statistical package (SPSS, Inc., Chicago, IL, USA).

\section{Results}

Antibacterial activity of the honey types against $S$. aureus and $P$. aeruginosa. Initial screening with the agar-well diffusion assay revealed that all the tested honey types exhibited antibacterial activity against $S$. aureus (Table II) and P. aeruginosa (Table III). In any case, the antibacterial effects exerted by the tested honey types (including Manuka honey) were more potent against $S$. aureus, as demonstrated by larger inhibition zones, compared to the effects against $P$. aeruginosa. A Spearman's correlation analysis was performed using the data of the well diffusion assay for $S$. aureus and P. aeruginosa (Table IV). This analysis revealed that there was no correlation between the antimicrobial activities of honey against these two bacterial species.

Determination of MIC values. The MIC values of the tested honey types against $S$. aureus were variable [3.125-12.5\% (v/v)]. By comparison, the MIC value of Manuka honey has been determined at $6.25 \%(\mathrm{v} / \mathrm{v})$. Seven honey types (nos. 1, 3, 10, 17, 18, 19 and 20) exhibited a lower MIC value than Manuka honey (Table II). Similarly, the MIC values of the tested honey types against $P$. aeruginosa ranged from $6.25-12.5 \%(\mathrm{v} / \mathrm{v})$, while the MIC value of Manuka honey was determined at $12.5 \%(\mathrm{v} / \mathrm{v})$. Nine honey types (nos. 8, 10, 12, 14, 15, 17, 18, 20, 21) exhibited a lower MIC value than Manuka honey (Table III). 
Table II. Antibacterial activity of honeys against Staphylococcus aureus in comparison to Manuka honey in agar well diffusion and MIC assays.

\begin{tabular}{|c|c|c|c|c|c|c|}
\hline \multirow[b]{2}{*}{ Honey code no. } & \multicolumn{2}{|c|}{ Well diffusion assay } & \multicolumn{2}{|c|}{$\mathrm{MIC} \%(\mathrm{v} / \mathrm{v})$} & \multirow{2}{*}{$\begin{array}{c}\mathrm{MIC} \%(\mathrm{v} / \mathrm{v})+ \\
\text { catalase }^{\mathrm{b}} \\
\text { honey }\end{array}$} & \multirow{2}{*}{$\begin{array}{c}\text { MIC } \%(\mathrm{v} / \mathrm{v})+ \\
\text { proteinase } \mathrm{K}^{\mathrm{b}} \\
\text { honey }\end{array}$} \\
\hline & Honey & Manuka MGO 550 & Honey & Manuka MGO 550 & & \\
\hline 1 & $22 \pm 0.5 \mathrm{~mm}^{\mathrm{a}}$ & $18 \pm 1.5 \mathrm{~mm}^{\mathrm{a}}$ & 3.125 & 6.250 & 25.0 & 3.125 \\
\hline 2 & $20 \pm 1.0 \mathrm{~mm}$ & $18 \pm 1.0 \mathrm{~mm}$ & 6.250 & 6.250 & 25.0 & 6.250 \\
\hline 3 & $23 \pm 0.5 \mathrm{~mm}$ & $18 \pm 3.0 \mathrm{~mm}$ & 3.125 & 6.250 & 25.0 & 6.250 \\
\hline 4 & $20 \pm 0.5 \mathrm{~mm}$ & $18 \pm 1.0 \mathrm{~mm}$ & 6.250 & 6.250 & 25.0 & 6.250 \\
\hline 5 & $17 \pm 0.5 \mathrm{~mm}$ & $16 \pm 1.0 \mathrm{~mm}$ & 12.500 & 6.250 & 25.0 & 12.500 \\
\hline 6 & $20 \pm 2.0 \mathrm{~mm}$ & $15 \pm 1.5 \mathrm{~mm}$ & 6.250 & 6.250 & 12.5 & 6.250 \\
\hline 7 & $20 \pm 0.5 \mathrm{~mm}$ & $16 \pm 1.0 \mathrm{~mm}$ & 6.250 & 6.250 & 25.0 & 6.250 \\
\hline 8 & $21 \pm 3.0 \mathrm{~mm}$ & $16 \pm 1.0 \mathrm{~mm}$ & 6.250 & 6.250 & 12.5 & 6.250 \\
\hline 9 & $21 \pm 0.5 \mathrm{~mm}$ & $16 \pm 0.5 \mathrm{~mm}$ & 6.250 & 6.250 & 25.0 & 6.250 \\
\hline 10 & $21 \pm 0.5 \mathrm{~mm}$ & $15 \pm 1.0 \mathrm{~mm}$ & 3.125 & 6.250 & 25.0 & 6.250 \\
\hline 11 & $18 \pm 2.0 \mathrm{~mm}$ & $15 \pm 1.0 \mathrm{~mm}$ & 6.250 & 6.250 & 25.0 & 6.250 \\
\hline 12 & $21 \pm 2.0 \mathrm{~mm}$ & $15 \pm 2.0 \mathrm{~mm}$ & 6.250 & 6.250 & 50.0 & 6.250 \\
\hline 13 & $22 \pm 1.0 \mathrm{~mm}$ & $17 \pm 1.0 \mathrm{~mm}$ & 6.250 & 6.250 & $\mathrm{ND}^{\mathrm{c}}$ & ND \\
\hline 14 & $17 \pm 1.0 \mathrm{~mm}$ & $16 \pm 1.0 \mathrm{~mm}$ & 6.250 & 6,250 & ND & ND \\
\hline 15 & $17 \pm 2.0 \mathrm{~mm}$ & $18 \pm 1.0 \mathrm{~mm}$ & 6.250 & 6.250 & ND & ND \\
\hline 16 & $16 \pm 0.0 \mathrm{~mm}$ & $16 \pm 1.0 \mathrm{~mm}$ & 6.250 & 6.250 & ND & ND \\
\hline 17 & $23 \pm 2.0 \mathrm{~mm}$ & $19 \pm 0.0 \mathrm{~mm}$ & 3.125 & 6.250 & 25.0 & 6.250 \\
\hline 18 & $20 \pm 0.0 \mathrm{~mm}$ & $17 \pm 1.0 \mathrm{~mm}$ & 3.125 & 6.250 & 12.5 & 3.125 \\
\hline 19 & $16 \pm 1.0 \mathrm{~mm}$ & $16 \pm 1.0 \mathrm{~mm}$ & 3.125 & 6.250 & 12.5 & 6.250 \\
\hline 20 & $17 \pm 1.0 \mathrm{~mm}$ & $16 \pm 1.0 \mathrm{~mm}$ & 3.125 & 6.250 & 12.5 & 3.125 \\
\hline 21 & $18 \pm 1.0 \mathrm{~mm}$ & $15 \pm 1.0 \mathrm{~mm}$ & 6.250 & 6.250 & ND & ND \\
\hline
\end{tabular}

${ }^{\mathrm{a}}$ Mean values of inhibition zones $\pm \mathrm{SD}$. ${ }^{\mathrm{b}} \mathrm{MIC}$ values of catalase- or proteinase K-treated honey types. ${ }^{\mathrm{c} N D}$, not determined.

The antibacterial activity of the honey types is attributed to hydrogen peroxide and proteinaceous compounds. In order to investigate the mechanisms which may contribute to the antibacterial activity, the honey types demonstrating a high antibacterial activity were treated with catalase and proteinase K. All the catalase-treated honey types exhibited higher MIC values against S. aureus than the untreated honey types, indicating that hydrogen peroxide exerts significant antibacterial activity. Furthermore, 4 proteinase K-treated honey types (nos. 3, 10, 17 and 19) exhibited higher MIC values against $S$. aureus, indicating the presence of antibacterial proteinaceous compounds (Table II). Similarly, all the catalase-treated honey types exhibited higher MIC values against $P$. aeruginosa, while 6 proteinase $\mathrm{K}$-treated honey types (nos. 8, 10, 12, 14, 15 and 21) exhibited higher MIC values compared to the untreated samples, indicating the presence of antibacterial proteinaceous compounds (Table III).

Antioxidant activity of the different honey types. Two free radical scavenging assays, DPPH and $\mathrm{ABTS}^{\circ+}$, were used for assessing the antioxidant activity of the honey types. The $\mathrm{IC}_{50}$ values of the honey types exhibiting the concentration that caused 50\% scavenging of free radicals are presented in Fig. 1. The lower the $\mathrm{IC}_{50}$ value, the higher the antioxidant activity. In DPPH assay, the $\mathrm{IC}_{50}$ values ranged from 7.5 (sample 8) to $109.0 \mathrm{mg} / \mathrm{ml}$ (sample 5) (Fig. 1). A strong DPPH radical scavenging activity was also exhibited by honey type nos. 3, 4 and 1 , with $\mathrm{IC}_{50}$ values of $10.0,11.5$ and $16.0 \mathrm{mg} / \mathrm{ml}$, respectively (Fig. 1). In the $\mathrm{ABTS}^{\bullet+}$ assay, the $\mathrm{IC}_{50}$ values ranged from 4.5 (sample 8) to $81.0 \mathrm{mg} / \mathrm{ml}$ (sample 11) (Fig. 1). Apart from honey type no. 8 , in that assay, honey sample nos. 4,13 and 7 exhibited potent antioxidant activity, with $\mathrm{IC}_{50}$ values of 10.0, 17.5 and $19.0 \mathrm{mg} / \mathrm{ml}$, respectively (Fig. 1). Although some samples (e.g., 8, 4 and 13) exhibited similar antioxidant activity in both assays, the statistical comparison between the two assays revealed a moderate significant correlation $(\mathrm{r}=0.574, \mathrm{P}<0.05)$ (Table IV). Manuka honey exhibited a weak antioxidant activity $\left(\mathrm{IC}_{50}, 68.0 \mathrm{mg} / \mathrm{ml}\right)$ in DPPH assay and a moderate activity in $\mathrm{ABTS}^{\cdot+}$ assay $\left(\mathrm{IC}_{50}, 21.0 \mathrm{mg} / \mathrm{ml}\right)$ compared to the other honey types (Fig. 1).

Correlation analysis was performed between the $\mathrm{IC}_{50}$ values of the DPPH and ABTS $^{\cdot+}$ assays and values from well diffusion assay for either S. aureus or P. aeruginosa. The analysis revealed that there was no significant correlation between the antioxidant and antimicrobial activities (Table IV).

Four honey types (nos. 3, 4, 7 and 8), which exhibited a high antioxidant activity, were converted to powder using the freeze drying method. These powder samples were also examined for their antioxidant activity using $\mathrm{ABTS}^{\cdot+}$ assay (Table V). The results revealed that, apart from honey type no. 7 , the $\mathrm{IC}_{50}$ values 
Table III. Antibacterial activity of honeys against Pseudomonas aeruginosa in comparison to Manuka honey in agar well diffusion and MIC assays.

\begin{tabular}{|c|c|c|c|c|c|c|}
\hline \multirow[b]{2}{*}{ Honey code no. } & \multicolumn{2}{|c|}{ Well diffusion assay } & \multicolumn{2}{|c|}{$\mathrm{MIC} \%(\mathrm{v} / \mathrm{v})$} & \multirow{2}{*}{$\begin{array}{c}\mathrm{MIC} \%(\mathrm{v} / \mathrm{v})+ \\
\text { catalase }^{\mathrm{b}} \\
\text { honey }\end{array}$} & \multirow{2}{*}{$\begin{array}{c}\mathrm{MIC} \%(\mathrm{v} / \mathrm{v})+ \\
\text { proteinase } \mathrm{K}^{\mathrm{b}} \\
\text { honey }\end{array}$} \\
\hline & Honey & Manuka MGO 550 & Honey & Manuka MGO 550 & & \\
\hline 1 & $18 \pm 1 \mathrm{~mm}^{\mathrm{a}}$ & $12 \pm 0 \mathrm{~mm}^{\mathrm{a}}$ & 12.50 & 12.50 & 25.00 & 12.50 \\
\hline 2 & $14 \pm 1 \mathrm{~mm}$ & $13 \pm 0 \mathrm{~mm}$ & 12.50 & 12.50 & 25.00 & 12.50 \\
\hline 3 & $14 \pm 2 \mathrm{~mm}$ & $12 \pm 1 \mathrm{~mm}$ & 12.50 & 12.50 & 25.00 & 12.50 \\
\hline 4 & $16 \pm 1 \mathrm{~mm}$ & $13 \pm 1 \mathrm{~mm}$ & 12.50 & 12.50 & 25.00 & 12.50 \\
\hline 5 & $16 \pm 1 \mathrm{~mm}$ & $13 \pm 0 \mathrm{~mm}$ & 12.50 & 12.50 & 25.00 & 12.50 \\
\hline 6 & $15 \pm 1 \mathrm{~mm}$ & $14 \pm 1 \mathrm{~mm}$ & 12.50 & 12.50 & 25.00 & 12.50 \\
\hline 7 & $16 \pm 2 \mathrm{~mm}$ & $13 \pm 2 \mathrm{~mm}$ & 12.50 & 12.50 & 25.00 & 12.50 \\
\hline 8 & $16 \pm 1 \mathrm{~mm}$ & $14 \pm 1 \mathrm{~mm}$ & 6.25 & 12.50 & 25.00 & 12.50 \\
\hline 9 & $14 \pm 2 \mathrm{~mm}$ & $9 \pm 0 \mathrm{~mm}$ & 12.50 & 12.50 & 25.00 & 12.50 \\
\hline 10 & $16 \pm 1 \mathrm{~mm}$ & $14 \pm 0 \mathrm{~mm}$ & 6.25 & 12.50 & 25.00 & 12.50 \\
\hline 11 & $13 \pm 1 \mathrm{~mm}$ & $7 \pm 5 \mathrm{~mm}$ & 12.50 & 12.50 & 25.00 & 12.50 \\
\hline 12 & $15 \pm 2 \mathrm{~mm}$ & $8 \pm 1 \mathrm{~mm}$ & 6.25 & 12.50 & 25.00 & 12.50 \\
\hline 13 & $14 \pm 1 \mathrm{~mm}$ & $11 \pm 1 \mathrm{~mm}$ & 12.50 & 12.50 & 25.00 & 12.50 \\
\hline 14 & $10 \pm 1 \mathrm{~mm}$ & $9 \pm 1 \mathrm{~mm}$ & 6.25 & 12.50 & 25.00 & 12.50 \\
\hline 15 & $15 \pm 1 \mathrm{~mm}$ & $11 \pm 1 \mathrm{~mm}$ & 6.25 & 12.50 & 25.00 & 12.50 \\
\hline 16 & $12 \pm 1 \mathrm{~mm}$ & $10 \pm 1 \mathrm{~mm}$ & 12.50 & 12.50 & 25.00 & 12.50 \\
\hline 17 & $13 \pm 0 \mathrm{~mm}$ & $10 \pm 0 \mathrm{~mm}$ & 6.25 & 12.50 & 25.00 & 6.25 \\
\hline 18 & $13 \pm 1 \mathrm{~mm}$ & $10 \pm 0 \mathrm{~mm}$ & 6.25 & 12.50 & 12.50 & 6.25 \\
\hline 19 & $11 \pm 0 \mathrm{~mm}$ & $9 \pm 0 \mathrm{~mm}$ & 12.50 & 12.50 & 25.00 & 12.50 \\
\hline 20 & $12 \pm 1 \mathrm{~mm}$ & $10 \pm 0 \mathrm{~mm}$ & 6.25 & 12.50 & 12.50 & 6.25 \\
\hline 21 & $10 \pm 1 \mathrm{~mm}$ & $10 \pm 0 \mathrm{~mm}$ & 6.25 & 12.50 & 12.50 & 12.50 \\
\hline
\end{tabular}

${ }^{\mathrm{a}}$ Mean values of inhibition zones $\pm \mathrm{SD} .{ }^{\mathrm{b}} \mathrm{MIC}$ values of catalase- or proteinase K-treated honey types.

Table IV. Correlation coefficient (r) values estimated from correlation analysis between values of DPPH, ABTS, TPC and well diffusion assays in S. aureus and P. aeruginosa of honey samples.

\begin{tabular}{|c|c|c|c|c|c|}
\hline & DPPH & ABTS & TPC & Well diffusion assay S. aureus & Well diffusion assay P. aeruginosa \\
\hline DPPH & & $0.574^{\mathrm{a}}$ & -0.371 & -0.055 & 0.064 \\
\hline ABTS & & & -0.457 & -0.003 & 0.260 \\
\hline TPC & & & & 0.176 & $-0.567^{\mathrm{a}}$ \\
\hline Well diffusion assay & & & & & -0.031 \\
\hline S. aureus & & & & & \\
\hline
\end{tabular}

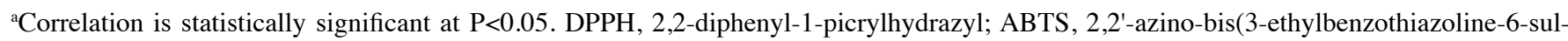
phonic acid; TPC, total polyphenolic content; P. aeruginosa, Pseudomonas aeruginosa; S. aureus, Staphylococcus aureus.

of the honey types were similar before and after powder preparation, which suggested that the freeze drying method did not affect their antioxidant activity (Table V and Fig. 1).

Total polyphenolic content (TPC) of the honey types. Since plant polyphenols are known as strong antioxidants, the TPC of the honey samples tested for their free radical-scavenging ability was measured in order to determine whether the polyphenolic content significantly contributed to their antioxidant activity. The TPC of the honey samples, as measured by the Folin-Ciocalteu method, ranged from 0.55 (sample 11) to $0.92 \mathrm{mg} \mathrm{GAE} / \mathrm{gr}$ sample (samples 4 and 8) (Table I). Honey sample no. 6 also had a high TPC (Table I). Manuka honey had a moderate TPC $(0.71 \mathrm{mg}$ GAE/gr sample) compared to other honey types (Table I).

TPC was also measured in the powder samples (Table V). The results revealed that powder preparation by the freeze drying method reduced the TPC in all the samples (by 21-32\%) (Tables I and V).

Statistical correlation analysis was also performed in order to estimate any correlation between the TPC and DPPH or ABTS ${ }^{+}$ 
Table V. Antioxidant capacity and TPC of the honey powders.

\begin{tabular}{lcc}
\hline Honey code no. & $\mathrm{ABTS}^{\cdot+} \mathrm{IC}_{50}(\mathrm{mg} / \mathrm{ml})^{\mathrm{a}}$ & $\mathrm{TPC}^{\mathrm{b}}$ \\
\hline 3 & $23.0 \pm 0.9$ & 0.52 \\
4 & $11.0 \pm 0.2$ & 0.72 \\
7 & $35.0 \pm 3.5$ & 0.40 \\
8 & $5.5 \pm 0.3$ & 0.67
\end{tabular}

aValues are the means \pm SD of at least 2 separate triplicate experiments. ${ }^{\text {bTPC }}$ was expressed as $\mathrm{mg}$ of gallic acid/g sample. TPC, total polyphenolic content; $\mathrm{ABTS}^{*+}, 2,2^{\prime}$-azino-bis(3-ethylbenzothiazoline-6-sulphonic acid.

radical scavenging activity (Table IV). This analysis revealed that there was a low non-significant negative correlation between the TPC and DPPH or $\mathrm{ABTS}^{-+}$assays $(\mathrm{r}=-0.371$ and $\mathrm{r}=-0.457$ respectively; $\mathrm{P}>0.05$ ) (Table IV). However, although there was not a high correlation between the TPC and antioxidant activity (Table IV), when looking at TPC and DPPH or $\mathrm{ABTS}^{++}$values of each honey type separately, then it can be observed that some honey types (e.g., nos. 4 and 8) with a high TPC also had a high antioxidant activity (Table I and Fig. 1).

Some polyphenols have also been reported to exhibit antimicrobial activity (26). Therefore, correlation analysis was performed between the TPC values and the values of well diffusion assay for either S. aureus or P. aeruginosa (Table IV). No correlation was observed between TPC and well diffusion assay for $S$. aureus, although there was a significant moderate negative correlation $(\mathrm{r}=-0.567 ; \mathrm{P}<0.05)$ between TPC and well diffusion assay for P. aeruginosa (Table IV).

\section{Discussion}

Olympus is the highest Greek mountain located in central Greece and is characterized by a high plant biodiversity (1,500 plant species of which 26 are endemic) (20). It is known that chemical composition and bioactivity of honey are greatly affected by the botanical and entomological source, as well as by the climate and geographical location $(4,5)$. Therefore, investigating the bioactivity of honey types derived from the Mt. Olympus area is of great interest.

In this study, 21 honey types derived from the Mt. Olympus area were screened for their antibacterial activity compared to Manuka honey by two different methods. Initial screening with the agar well diffusion assay demonstrated that all tested honey types exhibited antibacterial activity against $S$. aureus and $P$. aeruginos $a$. Nevertheless, the tested honey types demonstrated smaller inhibition zones of $P$. aeruginosa compared to those of $S$. aureus, thus indicating that $P$. aeruginosa is less susceptible to the antibacterial activity of honey. This finding is in accordance with the findings of previous studies $(7,27,28)$, possibly reflecting a higher intrinsic resistance of $P$. aeruginosa to the antibacterial potency of honey. Of note, Spearman's correlation analysis did not reveal any significant correlation of the antibacterial activity of honey against the two tested pathogens, suggesting that there was variability regarding the distinct antibacterial mechanisms and potency among the tested honey types.
It is generally accepted that MIC measurement in broth is a more sensitive and quantitatively accurate method with which to study the antimicrobial activity of honey compared to agar well diffusion assay, as the diffusion rates of active substances may be slower in agar than in broth $(7,16,29)$. Therefore, the MIC values of the honey types were determined in broth using a spectrophotometric-based assay. The MIC values demonstrated a high antibacterial activity of the honey types against both tested pathogens, particularly S. aureus, as it was documented by lower MIC values, which was in accordance with data obtained by the agar well diffusion assay.

Of note, 7 and 9 of the tested honey types demonstrated lower MICs than Manuka honey against S. aureus and P. aeruginosa, respectively. The antibacterial activity of the honey types against both pathogens may be attributed mainly to hydrogen peroxide, as illustrated by sharply elevated MIC values (up to 8-fold) following treatment with catalase. Indeed, hydrogen peroxide measurements in honey types derived from Mt. Olympus have exhibited high concentrations of hydrogen peroxide, which reflect its contribution to the antibacterial activity (unpublished data). On the contrary, methylglyoxal could not be detected in tested honey types (unpublished data). Apart from hydrogen peroxide, unidentified proteinaceous compounds of some honey types contributed to antibacterial activity against both pathogens, as it was demonstrated by their elevated MIC values following treatment with proteinase K. Of note, the antibacterial activity of some honey types (e.g., 17) against one of the two tested bacterial strains may be solely attributed to hydrogen peroxide, while hydrogen peroxide and proteinaceous compounds contributed to antibacterial activity of the same honey type against the second tested pathogen. Thus, this difference reflected an altered bacterial susceptibility due to distinct antibacterial mechanisms of honey against the two tested microorganisms.

In addition to its nutritional value, the antioxidant activity of honey is also considered important for human health $(1,17)$. For example, the modulation of oxidative stress has been suggested as one of the mechanisms through which honey exerts chemopreventive effects against cancer (1). In this study, the two most frequently used methods for assessing free radical scavenging ability were performed, the DPPH and $\mathrm{ABTS}^{\circ+}$ assays. These two free radical scavenging assays revealed that the $\mathrm{IC}_{50}$ values ranged from 7.5-109 $\mathrm{mg} / \mathrm{ml}$ for DPPH assay and from $4.5-81 \mathrm{mg} / \mathrm{ml}$ for $\mathrm{ABTS}^{++}$assay. These values are in accordance with data from similar studies on the antioxidant activity of raw honey samples, that is, samples were not processed for obtaining extracts enriched in bioactive compounds (30-32). Thus, some honey types (e.g., 3, 4, 8 and 13) that exhibited the lowest $\mathrm{IC}_{50}$ values had an exceptionally high antioxidant activity compared to the literature. It is noteworthy, that in both DPPH and $\mathrm{ABTS}^{*+}$ assays, the most potent honey type was no. 8 derived from mint, herbs and acacia as botanical sources. However, although there was a statistically significant correlation of the $\mathrm{IC}_{50}$ values between DPPH and $\mathrm{ABTS}^{++}$assays, this was not high. This finding indicated that in some honey types (e.g., 1, 3 and 5) with greatly variable $\mathrm{IC}_{50}$ values between the DPPH and $\mathrm{ABTS}^{-+}$assays, different compounds may be responsible for the scavenging of the respective radicals. Since the ABTS ${ }^{++}$ assay was carried out in aqueous solvent, while DPPH assay in methanol, hydrophilic compounds mainly accounted for the scavenging of $\mathrm{ABTS}^{*+}$ radical and non-polar compounds for 
the scavenging of DPPH radical. As regards the antioxidant activity of Manuka honey, it was shown to be one of the less potent honey types in DPPH assay, while in $\mathrm{ABTS}^{\cdot+}$ assay, it was the fifth most potent among the 13 tested honey types. These results suggested that the hydrophilic compounds of Manuka honey may mainly account for its antioxidant activity. The main antioxidant compounds of Manuka honey have been reported to be flavonoids and methyl syringate $(33,34)$. In other studies, the $\mathrm{IC}_{50}$ values of Manuka honey in DPPH and ABTS ${ }^{\bullet+}$ assays exhibited great variation (from $\sim 5-45 \mathrm{mg} / \mathrm{ml}$ ), which is probably due to the region from which honey is produced (35). Thus, the data from this study indicated that the most potent honey types derived from the Mt. Olympus region demonstrated antioxidant activity comparable or superior than that of Manuka honey.

As mentioned above, the antioxidant properties of honey are attributed at large to its polyphenols, and thus the TPC was estimated in all samples. The TPC values ranged from $0.55-0.92 \mathrm{mg}$ $\mathrm{GAE} / \mathrm{g}$ of sample. These values were in accordance to the TPC of the honey types, found in similar studies $(30,36,37)$. The TPC of Manuka honey $(0.71 \mathrm{mg} \mathrm{GAE} / \mathrm{g})$ was also in agreement with that of other studies $(32,38)$. As regards the influence of the TPC on the antioxidant activity, the findings were ambiguous. On the one hand, some of the honey types (e.g., nos. 4 and 8) with a high antioxidant activity also had the highest TPC values, while honey type no. 11 with a low TPC exhibited a weak antioxidant capacity. However, the statistical correlation analysis revealed that there was no significant correlation between either DPPH or $\mathrm{ABTS}^{*+}$ assay and TPC. Similarly, findings from previous studies on the association between TPC and antioxidant activity have been contradictory. For example, some studies have shown that the antioxidant activity depends on the TPC (30), while others have reported that apart from TPC, other factors may affect the antioxidant activity, such as the concentration of mineral contents, organic acids, vitamins (e.g., ascorbic acid), amino acids (e.g., proline, glycine and glutamic acid) and proteins $(37,39)$. These contradictions regarding the correlation of antioxidant activity and TPC may be explained by the botanical source of honey. Namely, there are plant species of which their antioxidant activity depends on the quantity of polyphenols, while in other plant species their antioxidant activity depends not on the quantity, but mainly on the chemical composition of polyphenols (23). The importance of chemical composition of honey's polyphenols is supported by the findings from the study by Sant'Ana et al (31), which demonstrated that the antioxidant activity of honey did not correlated with TPC, although it correlated with the amount of flavonoids, a subclass of polyphenols.

Furthermore, the Spearman's correlation analysis that was performed in this study demonstrated a significant correlation between TPC and antibacterial activity against $P$. aeruginosa, but not against $S$. aureus. This may indicate that polyphenols contributed to antibacterial activity likely by inhibiting virulence factors of $P$. aeruginosa, such as bacterial motility, adherence or biofilm formation as demonstrated in other studies (40).

Honey types which exhibit interesting bioactivities may be applied as medicines, sweeteners, or as flavorings and the development of biofunctional foods. However, for these applications, it is not always practical to use raw honey. Therefore, in this study, 4 honey types demonstrating a high antioxidant activity were converted to powder using a freeze drying method. The results revealed that after conversion to powder, all honey types, but one retained their antioxidant activity, although their TPC was reduced by $21-32 \%$. This indicated that encapsulation improved the antioxidant activity, possibly due to the better surface dispersion of the active polyphenolic spots which caused increased reactivity with free radicals. Thus, these findings suggested that this freeze drying method was effective for transforming honey to powder that can be used for different purposes in order to exploit the beneficial effects of honey on human health.

In conclusion, the present study was the first to examine antioxidant and antibacterial activities of honey types derived from Mt. Olympus which exhibits a high plant biodiversity. The tested honey types exerted antibacterial activity against $S$. aureus and P. aeruginosa. Importantly, some of the honey types had a higher antibacterial activity than Manuka honey, which is used as an alternative medicine. It seemed that hydrogen peroxide and proteinaceous compounds found in the honey types were responsible, at least in part, for the observed antibacterial activity. In addition, the TPC of the honey types accounted for the antibacterial activity against $P$. aeruginosa. Moreover, some of the tested honey types exerted higher free radical scavenging activity than Manuka honey. Thus, the antibacterial and antioxidant properties of honey types derived from Mt. Olympus, particularly those which are comparable or even superior to Manuka honey, warrant further investigation, as this may lead to applications in medicine and food industry.

\section{Acknowledgements}

Not applicable.

\section{Funding}

The present study was funded in part by the MSc programme 'Biotechnology, Nutrition and Environment' in the Department of Biochemistry and Biotechnology at the University of Thessaly and by a grant (to DM) from the Prefecture of Thessaly (contract no. 4954).

\section{Availability of data and materials}

The analyzed data sets generated during the study are available from the corresponding author on reasonable request.

\section{Authors' contributions}

DS, DM, DK, KP and DAS conceived and designed the experiments; NS, CT, SP, CA, AN, FK and SAA performed the experiments; DS and DM analyzed the data; DM, KP and DK provided the reagents/materials/analysis tools; DS and DM wrote the manuscript. All authors have read and approved the final manuscript.

\section{Ethics approval and consent to participate}

Not applicable.

\section{Consent for publication}

Not applicable. 


\section{Competing interests}

DAS is the Editor-in-Chief for the journal, but had no personal involvement in the reviewing process, or any influence in terms of adjudicating on the final decision, for this article.

\section{References}

1. Badolato M, Carullo G, Cione E, Aiello F and Caroleo MC: From the hive: Honey, a novel weapon against cancer. Eur J Med Chem 142: 290-299, 2017

2. Bogdanov S, Jurendic T, Sieber R and Gallmann P: Honey for nutrition and health: A review. J Am Coll Nutr 27: 677-689, 2008

3. Cornara L, Biagi M, Xiao J and Burlando B: Therapeutic properties of bioactive compounds from different honeybee products. Front Pharmacol 8: 412, 2017.

4. Escuredo O,Fernández-González M and Seijo MC: Differentiation of blossom honey and honeydew honey from Northwest Spain. Agriculture 2: 25-37, 2012.

5. BentabolManzanares A,HernándezGarcíaZ,RodríguezGaldónB, Rodríguez Rodríguez E and Díaz Romero C: Differentiation of blossom and honeydew honeys using multivariate analysis on the physicochemical parameters and sugar composition. Food Chem 126: 664-672, 2011.

6. Kuś PM, Szweda P, Jerković I and Tuberoso CI: Activity of Polish unifloral honeys against pathogenic bacteria and its correlation with colour, phenolic content, antioxidant capacity and other parameters. Lett Appl Microbiol 62: 269-276, 2016.

7. Anthimidou E and Mossialos D: Antibacterial activity of Greek and Cypriot honeys against Staphylococcus aureus and Pseudomonas aeruginosa in comparison to manuka honey. J Med Food 16: 42-47, 2013

8. Brudzynski K, Abubaker K and Wang T: Powerful bacterial killing by buckwheat honeys is concentration-dependent, involves complete DNA degradation and requires hydrogen peroxide. Front Microbiol 3: 242, 2012.

9. KwakmanPH,Te Velde AA,deBoerL,Vandenbroucke-GraulsCM and Zaat SA: Two major medicinal honeys have different mechanisms of bactericidal activity. PLoS One 6: e17709, 2011.

10. Kwakman PH, te Velde AA, de Boer L, Speijer D, VandenbrouckeGrauls CM and Zaat SA: How honey kills bacteria. FASEB J 24: 2576-2582, 2010.

11. Adams CJ, Boult CH, Deadman BJ, Farr JM, Grainger MN, ManleyHarris M and Snow MJ: Isolation by HPLC and characterisation of the bioactive fraction of New Zealand manuka (Leptospermum scoparium) honey. Carbohydr Res 343: 651-659, 2008.

12. Irish J, Blair S and Carter DA: The antibacterial activity of honey derived from Australian flora. PLoS One 6: e18229, 2011.

13. Hillitt KL, Jenkins RE, Spiller OB and Beeton ML: Antimicrobial activity of Manuka honey against antibiotic-resistant strains of the cell wall-free bacteria Ureaplasma parvum and Ureaplasma urealyticum. Lett Appl Microbiol 64: 198-202, 2017.

14. Carter DA, Blair SE, Cokcetin NN, Bouzo D, Brooks P, Schothauer R and Harry EJ: Therapeutic Manuka honey: No longer so alternative. Front Microbiol 7: 569, 2016.

15. Ronsisvalle S, Lissandrello E, Fuochi V, Petronio Petronio G, Straquadanio C, Crascì L, Panico A, Milito M, Cova AM, Tempera G and Furneri PM: Antioxidant and antimicrobial properties of Casteanea sativa Miller chestnut honey produced on Mount Etna (Sicily). Nat Prod Res 13: 1-8, 2017.

16. Tan HT, Rahman RA, Gan SH, Halim AS, Hassan SA, Sulaiman SA and Kirnpal-Kaur B: The antibacterial properties of Malaysian tualang honey against wound and enteric microorganisms in comparison to manuka honey. BMC Complement Altern Med 9: 34, 2009.

17. Meo SA, Al-Asiri SA, Mahesar AL and Ansari MJ: Role of honey in modern medicine. Saudi J Biol Sci 24: 975-978, 2017.

18. Burlando B and Cornara L: Honey in dermatology and skin care: A review. J Cosmet Dermatol 12: 306-313, 2013

19. Küpeli Akkol E, Orhan DD, Gürbüz I and Yesilada E: In vivo activity assessment of a 'honey-bee pollen mix' formulation. Pharm Biol 48: 253-259, 2010.

20. Vokou D, Petanidou T and Bellos D: Pollination ecology and reproductive potential of Jankaea heldreichii (Gesneriaceae); a tertiary relict on Mt Olympus, Greece. Biol Conserv 52: 125-133, 1990.

21. Polunin O: Flowers of Greece and the Balkans: A Field Guide. 1st edition. Oxford University Press, Oxford, 1987.
22. Patton T, Barrett J, Brennan J and Moran N: Use of a spectrophotometric bioassay for determination of microbial sensitivity to manuka honey. J Microbiol Methods 64: 84-95, 2006.

23. Stagos D, Portesis N, Spanou C, Mossialos D, Aligiannis N, Chaita E, Panagoulis C, Reri E, Skaltsounis L, Tsatsakis AM and Kouretas D: Correlation of total polyphenolic content with antioxidant and antibacterial activity of 24 extracts from Greek domestic Lamiaceae species. Food Chem Toxicol 50: 4115-4124, 2012.

24. Cano A, Acosta M and Arnao MB: A method to measure antioxidant activity in organic media: Application to lipophilic vitamins. Redox Rep 5: 365-370, 2000.

25. Singleton VL, Orthofer R and Lamuela-Raventos RM: Analysis of total phenols and other oxidation substrates and antioxidants by means of Folin-Ciocalteu reagent. Methods Enzymol 299: $152-178,1999$.

26. Marín L, Miguélez EM, Villar CJ and Lombó F: Bioavailability of dietary polyphenols and gut microbiota metabolism: Antimicrobial properties. Biomed Res Int 2015: 905215, 2015.

27. Deng J, Liu R, Lu Q, Hao P, Xu A, Zhang J and Tan J: Biochemical properties, antibacterial and cellular antioxidant activities of buckwheat honey in comparison to manuka honey. Food Chem 252: 243-249, 2018

28. Boateng J and Diunase KN: Comparing the antibacterial and functional properties of cameroonian and manuka honeys for potential wound healing-have we come full cycle in dealing with antibiotic resistance? Molecules 20: 16068-16084, 2015.

29. Szweda P: Antimicrobial activity of honey. In: Honey Analysis. Arnaut de Toledo VA (ed). InTech, Madrid, pp215-232, 2017. https://www.intechopen.com/books/honey-analysis/antimicrobialactivity-of-honey.

30. Alzahrani HA, Boukraa L, Bellik Y, Abdellah F, Bakhotmah BA, Kolayli S and Sahin H: Evaluation of the antioxidant activity of three varieties of honey from different botanical and geographical origins. Glob J Health Sci 4: 191-196, 2012.

31. Sant'Ana LD, Sousa JP, Salgueiro FB, Lorenzon MC and Castro RN: Characterization of monofloral honeys with multivariate analysis of their chemical profile and antioxidant activity. J Food Sci 77: C135-C140, 2012.

32. Can Z, Yildiz O, Sahin H, Akyuz Turumtay E, Silici S and Kolayli S: An investigation of Turkish honeys: Their physico-chemical properties, antioxidant capacities and phenolic profiles. Food Chem 180: 133-141, 2015.

33. Chan CW, Deadman BJ, Manley-Harris M, Wilkins AL, DG and Harry E: Analysis of the flavonoid component of bioactive New Zealand mānuka (Leptospermum scoparium) honey and the isolation, characterisation and synthesis of an unusual pyrrole. Food Chem 141: 1772-1781, 2013.

34. Alvarez-Suarez JM, Gasparrini M, Forbes-Hernández TY, Mazzoni L and Giampieri F: The composition and biological activity of honey: A focus on manuka honey. Foods 3: 420-432, 2014.

35. Stephens MJ, Schlothauer CR, Morris DB, Yang D, Fearnley L, Greenwood RD and Loomes MK: Phenolic compounds and methylglyoxal in some New Zealand manuka and kanuka honeys. Food Chem 120: 78-86, 2010.

36. Islam A, Khalil I, Islam N, Moniruzzaman M, Mottalib A, Sulaiman SA and Gan SH: Physicochemical and antioxidant properties of Bangladeshi honeys stored for more than one year. BMC Complement Altern Med 12: 177, 2012.

37. Rodríguez BA, Mendoza S, Iturriga MH and Castaño-Tostado E: Quality parameters and antioxidant and antibacterial properties of some Mexican honeys. J Food Sci 77: C121-C127, 2012.

38. Afrin S, Forbes-Hernandez TY, Gasparrini M, Bompadre S, Quiles JL, Sanna G, Spano N, Giampieri F and Battino M: Strawberry-tree honey induces growth inhibition of human colon cancer cells and increases ROS generation: A comparison with manuka honey. Int J Mol Sci 18: E613, 2017.

39. Pérez RA, Iglesias MT, Pueyo E, Gonzalez M and de Lorenzo C: Amino acid composition and antioxidant capacity of Spanish honeys. J Agric Food Chem 55: 360-365, 2007.

40. Daglia M: Polyphenols as antimicrobial agents. Curr Opin Biotechnol 23: 174-181, 2012

This work is licensed under a Creative Commons Attribution-NonCommercial-NoDerivatives 4.0 International (CC BY-NC-ND 4.0) License. 